Original Article (short paper)

\title{
Analysis of the relationship between personality traits and leadership characteristics of handball coaches of school teams in the state of Rio de Janeiro, Brazil
}

\author{
Dirceu Ribeiro Nogueira da Gama ${ }^{1}\left(\mathbb{1}\right.$, Rodolfo de Alkmim Moreira Nunes ${ }^{1}\left(\mathbb{D}\right.$, Juliana Brandão Pinto de Castro ${ }^{1}$, \\ Camilo Araújo Máximo de Souza ${ }^{2}$, Francisco Lopes Rodrigues Júnior ${ }^{1}{ }^{\circledR}$, Rodrigo Gomes de Souza Vale ${ }^{1,3}$ () \\ ${ }^{1}$ Universidade do Estado do Rio de Janeiro, Instituto de Educação Física e Desportos, Programa de \\ Pós-graduação em Ciências do Exercício e do Esporte, Rio de Janeiro, RJ, Brasil; ${ }^{2}$ Universidade do Estado do \\ Rio de Janeiro, Instituto de Educação Física e Desportos, Departamento de Esportes Coletivos, Rio de Janeiro, \\ RJ, Brasil, ${ }^{3}$ Universidade Estácio de Sá, Laboratório de Fisiologia do Exercício, Cabo Frio, RJ, Brasil
}

\begin{abstract}
Aim: This study aimed to investigate the relationship between personality traits and leadership characteristics of handball coaches of school teams in the state of Rio de Janeiro, Brazil. Method: The sample was composed of 31 male individuals (41.71 \pm 9.61 years) registered as coaches at the Federation of Student Sports of Rio de Janeiro (FEERJ). The data collection instruments were the Eysenck Personality Questionnaire, the Revised Leadership Scale for Sport and a sociodemographic questionnaire. Results: The Pearson correlation test showed a moderate negative correlation between working time as a coach and coach ages and Psychoticism (P); a moderate positive correlation between Extroversion (E) and Positive Feedback (PF) behavior; a moderate positive correlation between Neuroticism (N) and PF; a moderate positive correlation between $\mathrm{N}$ and autocratic behavior. The ANOVA revealed that coaches in the infantile category exhibited higher levels of $\mathrm{N}$ than those in the juvenile category. The Social Support (SS) given by the coaches of the junior categories presented superior levels to those of the juvenile category. The SS of the coaches of the infantile category showed higher levels than those of the juvenile category. Conclusion: It was concluded that certain personality traits are associated with the leadership characteristics of the investigated coaches.
\end{abstract}

Keywords: personality, coach, leadership, sports, sports psychology.

\section{Introduction}

The need to perform complex tasks often makes the choices for teamwork takes precedence over individual work. In general, the productivity of several people united, aiming to reach a common goal, tends to overcome the efforts of each one working alone ${ }^{1}$. However, the expected results of teamwork are more likely to occur if a competent authority conducts them. Among the characteristics of this authority, are a quality academic formation, the ability to identify and solve problems, be understanding, communicative, empathic, endowed with emotional balance and ability to keep the team focused on achieving the goals outlined ${ }^{1,2}$. In theories of organizational management, the subjects duly qualified to perform this function are called leaders. They present the so-called leadership characteristic, which is the ability to positively direct the behavior of individuals ${ }^{2}$.

Besides the organizational sphere, the presence of leaders is also important in the sporting context ${ }^{1,3}$. Their performance is crucial for athletes to engage in training sessions; be competitive; to seek victories; acquiring security; plan their careers and self-determine performance goals consistent with their physical and psychic states ${ }^{3,4}$. Often, the sports manager, the Physical Education teacher, and the coach are the subjects whose role is to lead their students and athletes ${ }^{5}$. Regarding the coach, since the 1950s, successive theoretical models have been built within the scope of sports psychology. The models intend to discriminate the qualities that must be developed to lead athletes of all levels and the variables involved in the exercise of that role ${ }^{5,6}$. In the last 20 years, the model that has become the main reference in the study of sports leadership is known by the name of Multidimensional Leadership Model ${ }^{6}$.

The Multidimensional Leadership Model seeks to situate the trainer's behavior from three parameters: the required behavior; the preferred behavior and the actual behavior. The required behavior has to do with the conduct that the coach must take based on the situational aspects of the working environment and the characteristics of the team members. The situational aspects refer to the profile of the modality (individual or competitive); the level of competitiveness (high-performance sport or training); the instance of intervention (schools, clubs, 
and universities); cultural values; current sports legislation and competition regulations. The characteristics of the team members are maturity; skill level; time of practice and degree of performance. The preferred behavior is one that athletes would like the coach to present from their personal motivations and expectations. The actual behavior refers to how the coach acts in the function of the experience acquired and, mainly, due to the personality characteristics ${ }^{6}$.

A person's personality is both the amount of information acquired throughout their socio-cultural interactions and a pattern of relatively stable and permanent traits that make them unique and distinct from others. The traits contribute to keeping behaviors regular overtime in the midst of the events. Hence, even though one person may resemble another in many points, this person still has a personality with own traits ${ }^{7,8}$.

Thus, the above information allows us to assume that a trainer's personality traits, insofar as they are conditioning factors that determine their actual behaviors, may interfere with the way they lead their athletes. Therefore, the present study aimed to investigate the relationships between personality traits and the leadership characteristics presented by handball coaches.

\section{Methods}

The present study corresponds to applied research of descriptive nature, of the Survey type, with transversal cut ${ }^{9}$. The research population consisted of 64 Brazilian handball coaches, all enrolled to direct the student teams participating in the $36^{\text {th }}$ edition of the Intercollegiate Championship of the State of Rio de Janeiro, Brazil, from August to November 2018 at the Nilton Santos Olympic Village. The list of competing teams was available on the website www.intercolegial.com. br from June 9, 2018.

As inclusion criteria, the subjects should be effectively registered as coaches in the Federation of Student Sports of Rio de Janeiro (FEERJ), Brazil. It was excluded 16 coaches from school teams whose records were overdue and 17 coaches not yet officially recognized by the organization. Thus, the final sample consisted of 31 trainers, all males, of the child $(n=10$; born between $01 / 01 / 2006$ and $31 / 12 / 2008)$, infantile $(n=10$; born between $01 / 01 / 2004$ and $31 / 12 / 2005)$ and juvenile $(n=11$; born between $01 / 01 / 2000$ and $31 / 12 / 2002$ ) categories. The athletes of these categories are aged between 10 and 18 years.

The Research Ethics Committee of the Rio de Janeiro State University (UERJ) approved the present study (CAAE: 24785614.0.0000.5259). The volunteers who agreed to participate in this study signed a consent form following by the Resolution No. 466/2012 of the Brazilian National Health Council and the Declaration of Helsinki.

\section{Procedures}

The accomplishment of this research counted on the collaboration of the organizing committee of the $36^{\text {th }}$ edition of the Intercollegiate Championship of the State of Rio de Janeiro. Information on age, time of practice and identification of the coaches' performance categories were collected through a supplementary questionnaire with a sociodemographic character. Each coach responded it individually after signing the consent form.

For the identification of the trainers' personality traits, the Eysenck Personality Questionnaire (EPQ) was applied. It consists of 88 questions with an objective "yes" or "no" input answers. In the EPQ, besides the evaluation of the traits of Extraversion/ Introversion (E), Neuroticism/Stability (N) and Psychoticism/ Socialization $(\mathrm{P})$, there is the Lie Scale $(\mathrm{L})$, which are questions regarding the control of the falsification or dissimulation of the answers. This questionnaire is translated into Portuguese and validated for the Brazilian population ${ }^{10}$. The EPQ has key scores for each trait; to each "correct" answer in a particular question of the trait, a point is added in the index. For the EPQ, it is considered for $\mathrm{E}$ scores between zero and 18 points; for $\mathrm{N}$ between zero and 23 points; for $\mathrm{P}$ between zero and 25 points; and for $\mathrm{L}$ between zero and 22 points.

The leadership characteristics measurement was made through the application of the Revised Leadership Scale for Sport (RLSS), the coach's self-perception version. This instrument has also been translated into Portuguese and validated for the Brazilian population ${ }^{11}$. The RLSS, the selfperception of the coach, is composed of 60 items distributed in 6 dimensions: Democratic Behavior or DB (12 items); Social Support or SS (8 items); Positive Feedback or PF (12 items); Training and Instruction or TI (10 items); Autocratic Behavior or AB (8 items) and Situational Consideration or SC (10 items). The respondent should evaluate the habitual attitudes through a Likert scale of 1 to 5 points, applied to 5 alternative answers: never ( 1 point); rarely ( 2 points); occasionally ( 3 points); often (4 points); and always (5 points). The total score ranges from 0 to 300 points. The scale has been considered appropriate because the items reflect how the coach handles athletes on a day-to-day basis.

\section{Statistical Analyses}

The data were analyzed by the IBM SPSS Statistics version 20.0 and presented as mean and standard deviation. The normality and homogeneity of the data were verified by the Shapiro-Wilk and Levene tests, respectively. One-way ANOVA was used, followed by Tukey's post hoc, for comparisons of the variables among the coaches' performance categories. The Pearson correlation test was used to analyze the associations between the study variables. The study admitted the value of $p<0.05$ for statistical significance.

\section{Results}

Table 1 shows the average values of age, working time as a coach, personality trait scores, and leadership characteristics of the handball coaches analyzed in the present study. 
Table 1. Descriptive results of the variables analyzed in the study $(n=31)$.

\begin{tabular}{|c|c|c|c|c|c|c|c|}
\hline & Mean & SD & p-value (SW) & & Mean & SD & p-value (SW) \\
\hline Age & 41.71 & 9.61 & 0.730 & $\overline{\mathrm{DB}}$ & 40.29 & 6.43 & 0.655 \\
\hline Work & 16.06 & 8.81 & 0.467 & SS & 31.65 & 4.94 & 0.265 \\
\hline $\mathrm{P}$ & 3.06 & 2.22 & 0.055 & $\mathrm{PF}$ & 53.26 & 5.16 & 0.052 \\
\hline $\mathrm{E}$ & 11.81 & 3.64 & 0.053 & $\mathrm{TI}$ & 44.90 & 3.53 & 0.090 \\
\hline $\mathrm{N}$ & 9.55 & 4.61 & 0.797 & $\mathrm{AB}$ & 25.32 & 4.85 & 0.422 \\
\hline $\mathrm{L}$ & 13.19 & 3.34 & 0.619 & $\mathrm{SC}$ & 43.19 & 5.78 & 0.051 \\
\hline
\end{tabular}

SD: Standard Deviation; SW: Shapiro-Wilk normality test; Work: working time as a coach; P: Psychoticism; E: Extraversion; N: Neuroticism; L: Lie scale; DB: Democratic Behavior; SS: Social Support; PF: Positive Feedback; TI: Training and Instruction; AB: Autocratic Behavior; SC: Situational Consideration.

In table 2, there is the correlation matrix between the Pearson correlation coefficient " $\mathrm{r}$ " and personality traits, age, working time as coach and leadership characteristics. The time working as a coach and the age of the coaches showed a moderate negative correlation with P. Between E and PF, there was a moderate positive correlation.
It was observed a moderate positive correlation between $\mathrm{N}$ and $\mathrm{PF}$. There was a moderate positive correlation between $\mathrm{N}$ and $\mathrm{AB}$.

Table 3 presents the comparison between the variables age, working time as a coach, personality trait scores and leadership characteristics by performance categories.

Table 2. Pearson correlation coefficient " $\mathrm{r}$ " and personality traits, age, working time as coach and leadership characteristics.

\begin{tabular}{|c|c|c|c|c|c|c|c|c|c|c|c|c|}
\hline & & Age & Work & $\mathbf{P}$ & $\mathbf{E}$ & $\mathbf{N}$ & $\mathbf{L}$ & DB & SS & PF & TI & $\mathbf{A B}$ \\
\hline \multirow[t]{2}{*}{ Work } & $\mathrm{r}$ & 0.881 & & & & & & & & & & \\
\hline & $\mathrm{p}$-value & 0.000 & & & & & & & & & & \\
\hline \multirow[t]{2}{*}{$\mathrm{P}$} & $\mathrm{r}$ & -0.449 & -0.438 & & & & & & & & & \\
\hline & $\mathrm{p}$-value & 0.011 & 0.014 & & & & & & & & & \\
\hline \multirow[t]{2}{*}{$\mathrm{E}$} & $\mathrm{r}$ & -0.068 & -0.037 & 0.084 & & & & & & & & \\
\hline & p-value & 0.715 & 0.843 & 0.653 & & & & & & & & \\
\hline \multirow[t]{2}{*}{$\mathrm{N}$} & $\mathrm{r}$ & 0.062 & 0.137 & 0.218 & -0.097 & & & & & & & \\
\hline & p-value & 0.742 & 0.463 & 0.239 & 0.604 & & & & & & & \\
\hline \multirow[t]{2}{*}{$\mathrm{L}$} & $\mathrm{r}$ & -0.019 & -0.024 & 0.007 & 0.061 & -0.187 & & & & & & \\
\hline & p-value & 0.919 & 0.897 & 0.969 & 0.745 & 0.314 & & & & & & \\
\hline \multirow[t]{2}{*}{ DB } & $\mathrm{r}$ & -0.003 & 0.146 & 0.169 & 0.061 & 0.169 & 0.115 & & & & & \\
\hline & $\mathrm{p}$-value & 0.988 & 0.433 & 0.363 & 0.745 & 0.364 & 0.537 & & & & & \\
\hline \multirow[t]{2}{*}{ SS } & $\mathrm{r}$ & -0.238 & -0.079 & 0.291 & 0.236 & 0.315 & 0.253 & 0.269 & & & & \\
\hline & p-value & 0.198 & 0.672 & 0.112 & 0.202 & 0.084 & 0.170 & 0.143 & & & & \\
\hline \multirow[t]{2}{*}{ PF } & $\mathrm{r}$ & -0.203 & -0.099 & 0.219 & 0.429 & 0.446 & 0.242 & 0.349 & 0.301 & & & \\
\hline & p-value & 0.273 & 0.598 & 0.236 & 0.016 & 0.012 & 0.189 & 0.044 & 0.100 & & & \\
\hline \multirow[t]{2}{*}{ TI } & $\mathrm{r}$ & 0.449 & 0.444 & 0.022 & 0.074 & 0.294 & 0.273 & 0.259 & 0.384 & 0.405 & & \\
\hline & $\mathrm{p}$-value & 0.011 & 0.012 & 0.906 & 0.694 & 0.109 & 0.138 & 0.159 & 0.033 & 0.024 & & \\
\hline \multirow[t]{2}{*}{$\mathrm{AB}$} & $\mathrm{r}$ & 0.217 & 0.197 & 0.035 & 0.000 & 0.439 & 0.076 & -0.042 & 0.054 & 0.367 & 0.354 & \\
\hline & p-value & 0.241 & 0.288 & 0.851 & 0.999 & 0.013 & 0.683 & 0.824 & 0.774 & 0.042 & 0.049 & \\
\hline \multirow[t]{2}{*}{$\mathrm{SC}$} & $\mathrm{r}$ & 0.140 & 0.323 & -0.037 & -0.076 & 0.374 & 0.052 & 0.502 & 0.088 & 0.547 & 0.285 & 0.348 \\
\hline & p-value & 0.453 & 0.076 & 0.842 & 0.685 & 0.038 & 0.783 & 0.004 & 0.638 & 0.001 & 0.120 & 0.045 \\
\hline
\end{tabular}

Work: working time as a coach; P: Psychoticism; E: Extraversion; N: Neuroticism; L: Lie scale; DB: Democratic Behavior; SS: Social Support; PF: Positive Feedback; TI: Training and Instruction; AB: Autocratic Behavior; SC: Situational Consideration.

Table 3. Mean and standard deviation of the variables analyzed and the coaches' performance categories.

\begin{tabular}{lccc}
\hline & Junior $(\mathbf{n}=\mathbf{1 0})$ & Infantile $(\mathbf{n}=\mathbf{1 0})$ & Juvenile $(\mathbf{n}=\mathbf{1 1})$ \\
\hline Age & $37.10 \pm 10.81$ & $43.20 \pm 9.44$ & $44.55 \pm 7.71$ \\
Work & $13.10 \pm 10.24$ & $17.80 \pm 9.60$ & $17.18 \pm 6.52$ \\
P & $3.50 \pm 2.46$ & $3.50 \pm 2.27$ & $2.27 \pm 1.90$ \\
E & $12.50 \pm 4.28$ & $12.10 \pm 3.70$ & $10.91 \pm 3.08$ \\
N & $9.40 \pm 3.44$ & $12.90 \pm 4.61^{*}$ & $6.64 \pm 3.67$ \\
L & $12.60 \pm 4.45$ & $14.40 \pm 3.03$ & $12.64 \pm 2.29$ \\
\hline
\end{tabular}

\begin{tabular}{lccc}
\hline & Junior $(\mathbf{n}=\mathbf{1 0})$ & Infantile $(\mathbf{n}=\mathbf{1 0})$ & Juvenile $(\mathbf{n}=\mathbf{1 1})$ \\
\hline DB & $38.50 \pm 5.89$ & $41.10 \pm 7.40$ & $41.18 \pm 6.23$ \\
SS & $33.70 \pm 4.22^{\#}$ & $34.30 \pm 3.71^{*}$ & $27.36 \pm 3.64$ \\
PF & $52.30 \pm 6.00$ & $55.00 \pm 5.31$ & $52.55 \pm 4.20$ \\
TI & $44.00 \pm 4.29$ & $46.10 \pm 3.45$ & $44.64 \pm 2.80$ \\
AB & $24.10 \pm 4.51$ & $27.50 \pm 5.28$ & $24.45 \pm 4.48$ \\
SC & $40.70 \pm 8.92$ & $45.00 \pm 3.33$ & $43.82 \pm 2.93$ \\
\hline
\end{tabular}

Work: working time as a coach; P: Psychoticism; E: Extraversion; N: Neuroticism; L: Lie scale; DB: Democratic Behavior; SS: Social Support; PF: Positive Feedback; TI: Training and Instruction; AB: Autocratic Behavior; SC: Situational Consideration; * $p<0.05$, Infantile vs. Juvenile; $\# p<0.05$ Junior vs. Juvenile. 
The ANOVA test applied to personality traits and the leadership characteristics of the coaches by performance category identified the existence of statistically significant differences in $\mathrm{N}(\mathrm{F}=6.673 ; p=0.004)$ and $\mathrm{SS}(\mathrm{F}=10.560 ; p<0.001)$. The coaches of the infantile category exhibited higher levels of $\mathrm{N}$ ( $p=0.003)$ than those of the juvenile category. The SS of the coaches of the child category presented levels superior to those of the juvenile category $(p=0.002)$. The SS of the coaches of the infantile category showed higher levels than those of the juvenile category $(p=0.001)$.

\section{Discussion}

The relationships between personality traits and the leadership characteristics presented by handball coaches of school teams in the state of Rio de Janeiro were analyzed in the present study. A negative and moderate correlation was observed between the working time as a coach and the age of the trainers with the P trait. This means that the handball coaches who remain for the longest time exercising this occupation are those in which the presence of the superego is striking ${ }^{12}$. Individuals with this trait tend to be sociable, interactive, and rate hard work as positive ${ }^{12,13}$. In addition, they see failures as learning opportunities and seek to develop effective mental strategies to overcome adversities ${ }^{13,14,15}$.

One of the assumptions of the Multidimensional Leadership Model points out that experience and personality correspond to factors linked to the actual behavior of the coach. However, this model does not show that they may also present some type of association among them ${ }^{6}$. Taking into account that practice time serves as an indicator of the experience accumulated by the coach over the career course, the present study, by acknowledging the validity of an empirical interrelationship between experience and personality, indicates that this assumption of the Model can be reviewed and improved.

The existence of personalities with outstanding superego presence was observed in the qualitative case study carried out by Mallet and Coulter ${ }^{16}$ with four Australian coaches with professional career times over 30 years. After the application and analysis of structured interviews, the authors concluded that the subjects investigated based their way of acting in the establishment of goals, cooperation, discipline, and collective planning. Similarly, Pan, Huang, and Lee ${ }^{17}$, through a Survey applied to 130 male and female basketball coaches in Taiwan schools, observed that those with greater professional longevity were the ones who most valued positively the effects of intense, systematic and planned training. These results converge with the findings of the present study.

There was also, in the present study, a moderate positive correlation between personality trait E and PF. Extroverted individuals excel in communicability, optimism, quick thinking, and jocosity ${ }^{12,18}$. The PF refers to the mental strengthening of the athlete through the double action of encouragement in the face of mistakes and rewards for efficient performance. Evidence holds that the coach's PF contributes to motivating athletes to train, develop selfconfidence, and cultivate fellowship ${ }^{19,20,21,22}$.

In a cross-sectional investigation of the Survey type, Soane, Butler, Stanton ${ }^{23}$ analyzed the perception of effective leadership that 122 Olympic-level English sailors had of their trainers, relating it with their personality traits. In the end, they found that the trainers considered effective leaders stood out by extroversion and the provision of positive individual feedback to each one during the training and regattas. Some of these coaches extrapolated the training and competition environment, even sending complimentary e-mail messages to their athletes. This result is consistent with the findings of the present study and reaffirms the importance of assertive leaders in the management of interpersonal relationships within the group ${ }^{24}$.

On the other hand, Schliermann, Stoltz, Anneken ${ }^{25}$ conducted a cross-sectional survey with 57 German soccer coaches involved in an initiation program for young people with cognitive disorders. The authors observed that subjects with introversion characteristics also showed efficiency in providing PF to the participants. When compared, the study in question and that of Soane, Butler, Stanton ${ }^{23}$ allow us to hypothesize that, as the degree of competitiveness and performance requirement of sports contexts increases, coaches with extroverted personality start to stand out the provision of PF. Further research is needed regarding the confirmation of this association. In terms of the Multidimensional Leadership $\mathrm{Model}^{6}$, such information shows that the actual behavior of encouraging, correcting, praising, and stimulating is relevant in motivating athletes to overcome difficulties, and does not depend on extraversion or introversion as personality traits.

The present study identified a moderate positive correlation between the personality trait $\mathrm{N}$ and the PF and $\mathrm{AB}$ leadership characteristics. The greater the $\mathrm{N}$ in a person, the lower the tolerance to situations of prolonged stress, which makes this person prone to excessive states of anxiety and emotional unrest $\mathrm{t}^{12,13}$. The $\mathrm{AB}$ presupposes that the trainer adopts unilateral attitudes, offering few opportunities for the athletes to participate in the decision-making about the conduction of the training process.

The positive correlation between $\mathrm{N}, \mathrm{PF}$, and $\mathrm{AB}$ found in the present study contradicts the results of the crosssectional survey conducted by Dixon, Turner, Gillman ${ }^{26}$ with 105 male soccer coaches. In it, the authors found that those more emotionally stressed in training and games tended to act authoritatively and offered little PF to athletes. One possible explanation is given by Dixon, Turner, Gillman ${ }^{26}$ where communicating PF requires accurate assessments of the causes of the mistakes and the correctness. Coaches with high levels of stress and anxiety present difficulties in making diagnoses of this nature because it is a task that requires the establishment of causal links, which are more accurately delineated when untimely emotions can be kept under control ${ }^{26,27}$.

In contrast, a transversal investigation conducted by Heidari and Arani ${ }^{18}$ with 86 handball coaches in Iran during an international championship showed that individuals with $\mathrm{N}$ 
profile might adopt different leadership strategies, including the combination of PF with AB. This is possible because, according to these authors, the emotional states of neurotic subjects may vary abruptly when changes occur in their subjective perceptions of environmental stress. Consequently, the means adopted to interact with other people reflect this circumstance. In the study by Heidari and Arani ${ }^{18}$, coaches with a neurotic profile modified leadership strategies, as they felt more relaxed or anxious during training and games. When it comes to the Multidimensional Leadership Model $^{6}$, it is possible to affirm that the coach with a strong neuroticist trait, depending on the feeling and reaction to environmental stress, shows oscillations in the real behaviors due to sudden changes in affections and mood. This circumstance can lead the coach to take unwanted actions with the athletes. Such attitudes negatively affect the confidence that athletes attribute to the coach to lead.

Regarding the personality traits by category of performance, it was verified in the present study that the coaches of the infantile category had higher levels of $\mathrm{N}$ compared to those in the juvenile category. The period between 12 and 14 years of age corresponds to the stage of entry into puberty of males. In it, complex physical and psychic transformations occur, such as the rapid growth and development of bone and muscle tissues, changes in body composition and loss of children's features ${ }^{28,29,30}$. These transformations have repercussions on the body image, perception of efficiency and social adjustment, often leading the puberty to exhibit ambiguous attitudes, ranging from insecurity and isolation to the questioning of the authorities, seeking autonomy and recognition of other youths $^{28}$. Accelerated gains in muscle mass and height at this stage are not accompanied by proportional increases in strength and coordinating abilities, making sports motor performance unstable and irregular ${ }^{30,31,32}$. Allen and Laborde ${ }^{33}$ recommend that coaches of this age group be patient, tolerant and able to mediate conflicts through the direct involvement of all involved. The authors further suggest that sports managers should frequently monitor these coaches, as inconstancy in the performance of sports motor skills by pubertal athletes may trigger the emergence of intense stress sensations and exacerbated emotional reactions. In extreme cases, Allen and Laborde ${ }^{33}$ endorse the provision of therapeutic support to coaches with this characteristic.

Coaches with low tolerance to stress are one of the causes of the abandonment of young talents of the sphere of the formation sport. Cross-sectional studies with basketball players, swimmers, artistic gymnasts and adolescent athletics practitioners in Hong Kong, Greece, Brazil, and Taiwan indicate that dropping out of sports practice may be related to the rebound caused by excessive reprimands by coaches towards other training colleagues ${ }^{27,34,35,36}$. This situation indicates that, from the point of view of the Multidimensional Leadership Model $^{6}$, when the actual behavior of the coach differs markedly from the preferential behavior that the athletes would like the coach to exhibit, a possible consequence is the athletes' withdrawal from continuing in sports practices.
The present study identified that SS given by coaches in the child and infantile categories presented higher levels than those offered by juvenile coaches. Coaches with this attitudinal bias seek to advise athletes on the best way to solve private problems and make the sport be seen as something important in their lives ${ }^{11,37}$.

Gardner, Magee, Vella ${ }^{38}$ conducted a survey with 313 Australian students who practice netball, soccer, dance, and swimming, whose ages ranged from 11 to 15 years. They observed that the more frequent the SS given by coaches to youngsters with a lower time of practice, the more the athletes self-declared motivated to train. Similarly, Reynolds and $\mathrm{McDonough}^{39}$ found in a study with 142 young American footballers aged 12-15 years that the desire for technical improvement was greater among individuals whose coaches provided incessant SS.

One limitation of the present study concerns its transverse nature since this approach does not allow identifying temporal variations of the leadership strategies adopted by the coaches according to the identification of their personality traits. Another limitation concerns the profile of the sample since only male trainers composed it.

\section{Conclusion}

The present study allows concluding that, in the case of the investigated coaches, certain personality traits were associated with the manifestation of some leadership characteristics. In the individuals where the E trait presented a higher score, the offer of PF to the athletes also stood out. As for the trainers in which the $\mathrm{N}$ trait preponderated, they presented both PF and AB. Therefore, the guiding hypothesis of the investigation according to which personality traits are associated with leadership characteristics was ratified. Additionally, there was a concentration of coaches with $\mathrm{N}$ trait in the junior category compared to the infantile and juvenile ones. Still, on the categories of performance, the junior and infantile coaches supplanted the juveniles in terms of SS.

Based on the observation of the previous factors, it can be said that extroverted coaches and directors of actions in line with positive social values are likely to have a longer sports career. Moreover, athletes run by coaches with this personality trait and leadership characteristic feel encouraged staying for longer in sports practice. In contrast, discontent is recurrent in the case of athletes trained by neurotic subjects.

Future studies should analyze the associations between personality traits and leadership characteristics, taking into account a longitudinal perspective, as well as the inclusion of female coaches in the sample.

\section{References}

1. Hunter J. O monge e o executivo: uma história sobre a essência da liderança. São Paulo: Sextante; 2004. 
2. Johnson P. Human resource management in changing organizational contexts. In: Collings D, Wood G, editors. Human resource management: a critical approach. New York: Routledge; 2009.

3. Cassidy T, Jones R, Potrac P. Understanding sports coaching: the social, cultural and pedagogical foundations of coaching practice. New York: Routledge; 2009.

4. Resende R, Gomes R, Vieira O. Liderança no futsal de alta competição: importância dos resultados desportivos. Motriz: J Phys Ed. 2013;19(2):502-12.

5. Horn T. Leadership effectiveness in the sport domain. In: Horn, T. (Ed.). Advances in sport psychology. Champaign, IL: Human Kinetics; 1992.

6. Chelladurai P. Managing organizations for sport \& Physical Education: systems perspective. Scottsdale, AR: Holcomb Hathaway; 2001.

7. Flores-Mendoza C, Ardila R, Gallegos M, Braga LS, Santiago BMC, Andrade DM. Hans Eysenck in Latin America: his influence in the psychology, the study of personality and individual differences. Pers Individ Dif. 2016;103:68-73.

8. Parks-Leduc L, Feldman G, Bardi A. Personality traits and personal values: a meta-analysis. Pers. Soc. Psychol. Rev. 2015;19(1):3-29.

9. Gerhardt TE, Silveira DT. Métodos de pesquisa. Porto Alegre: UFRGS; 2009.

10. 10. Tarrier N, Eysenck SBG, Eysenck HJ. National differences in personality; Brazil and England. Pers Individ Dif. 1980;1(2):164-71.

11. Costa IT, Samulski DM, Costa VT. Leadership profile to soccer coaches according to top Brazilian coaches. J. Phys. Educ. 2010;21(1):59-68.

12. Eysenck HJ, Nias DK, Cox DN. Advanced Behavioral Research Therapy. Sport and personality.1982;4(1):1-56.

13. Feist J, Feist G. Teorias da personalidade. 8. ed. Porto Alegre: McGraw Hill; 2015.

14. Menezes RP, Ramos NC, Marques RFR, Nunomura M. Teaching handball to U-16 and U-18 women's teams: coaches' perspective on the long-term. Motriz: J Phys Ed. 2018;24(4):e101838.

15. Sowthwick SM, Pietrzak RH, White G. Interventions to enhance resilience and resilience-related constructs in adults. In: Southwick SM, Litz BT, Charney D, Friemann MJ, editors. Resilience and mental health: challenges across the lifespan. New York: Cambridge University Press; 2011. p. 289-306.

16. Mallet CJ, Coulter TJ. The anatomy of a successful Olympic coach: actor, agent and author. Int Sport Coaching J. 2016;3:113-27.

17. Pan HW, Huang WY, Lee JY. A study on the personality tendency of male and female basketball coaches in South Taiwan schools. Int. j. phys. educ. sports health. 2018; 5(5):26-33.

18. Heidari M, Arani MR. Relationship between five personality factors with decision making styles of coaches. Sport Science. 2017;10(1):70-6.

19. Halperin I, Chapman DW, Martin DT, Abbiss C, Wulf G. Coaching cues in amateur boxing: an analysis of ringside feedback provided between rounds of competition. Psychol Sport Exerc. 2016;25:44-50.
20. King J, Roberts C, Hard S, Ardern CL. Want to improve return to sport outcomes following injury? Empower, engage, provide feedback and be transparent: 4 habits! Br. J. Sports Med. 2018;1-2. doi:10.1136/bjsports-2018-099109.

21. Mouratidis A, Vansteenkiste M, Lens W, Sideridis G. The motivating role of positive feedback in sport and Physical Education: evidence for a motivational model. J Sport Exercise Psy. 2008;30:240-68.

22. Vierimaa M, Bruner MW, Côté J. Positive youth development and observed athlete behavior in recreational sport. PLoS ONE. 2018;13(1):e0191936.

23. Soane E, Butler C, Stanton E. Followers' personality, transformational leadership and performance. Sport, Business and Management. 2015;5(1):65-78.

24. Judge TA, Bono JE, Ilies R, Gerhardt MW. Personality and leadership: a qualitative and quantitative review. J Appl Psychol. 2002;87(4):765-80.

25. Schliermann R, Stoltz I, Anneken V. The sports background, personality, attitudes and social competences of coaches and assistants coaches in the just soccer program for pupils with intellectual disabilities. Human Movement. 2014;15(3):177-85.

26. Dixon M, Turner MJ, Gillman J. Examining the relationships between challenge and threat cognitive appraisals and coaching behaviours in football coaches. J.Sports Sci. 2017;35(24):2446-52.

27. Bekiari A, Syrmpas I. Coaches' verbal aggressiveness and motivational climate as predictors of athletes' satisfaction. British J Ed Soc Behav Sci. 2015;9(4):318-29.

28. Labbrozzi D, Robazza C, Bertollo M, Bucci I, Bortoli L. Pubertal development, physical self-perception, and motivation toward physical activity in girls. J. Adolesc. 2013;36:759-65.

29. Luciano AP, Bertoli CJ, Adami F, Abreu LC. Nível de atividade física em adolescentes saudáveis. Rev Bras Med Esporte. 2016;22(3):191-4.

30. Šimonek J. The effect of intervention on the changes of coordination factors in the youth sports preparation. Sport Science. 2016;9(Suppl 2):77-81. .

31. Holden S, Boreham C, Delahunt E. Sex differences in landing biomechanics and postural stability during adolescence: a systematic review with meta-analyses. Sports Med. 2016;46(2):241-53.

32. Holienka M, Babic M, Doležajová L, Šelinger P, Musilová E. Motor performance of young soccer players depending on biological age. EQOL Journal. 2017;9(2):19-23.

33. Allen MS, Laborde S. The role of personality in sport and physical activity. Curr. Dir. Psychol. Sci. 2014;23(6):460-5.

34. Chan DK, Lonsdale C, Fung HH. Influences of coaches, parents, and peers on the motivational patterns of child and adolescent athletes. Scand J Med Sci Spor. 2012;22(4):558-68.

35. Hassan AR, Lam MHS, Ku S, Li WHC, Lee KY, Ho E, Flint SW, Wong ASW. The reasons of dropout of sport in Hong Kong school athletes. J. Health Psychol. Res. 2017;5:6766.

36. Nunomura M, Okade Y, Carrara P. How much artistic gymnastics coaches know about their gymnasts' motivationSci. Gymnast. J. 2012;4(2):27-37. 
37. Noce F, Teixeira TM, Lopes MC, Samulski DM, Souza PRC. El liderazgo de los entrenadores de fútbol sala. Ver. Psicol. Deporte. 2013;22(1):11-7.

38. Gardner LA, Magee CA, Vella SA. Social climate profiles in adolescent sports: associations with enjoyment and intention to continue. J. Adolesc. 2016;52:112-23.

39. Reynolds AJ, McDonough MH. Moderated and mediated effects of coach autonomy support, coach involvement, and psychological need satisfaction on motivation in youth soccer. Sport Psychol. 2015;29(1):51-61.

\section{Corresponding author}

Juliana Brandão Pinto de Castro

Rua São Francisco Xavier, 524, Pavilhão João Lira Filho, $9^{\circ}$ andar, Bloco F, sala 9134, Maracanã, Rio de Janeiro, RJ, Brasil, CEP: 20550-900

Email: julianabrandaoflp@hotmail.com

Manuscript received on June 9, 2019

Manuscript accepted on July 14, 2019

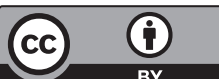

Motriz. The Journal of Physical Education. UNESP. Rio Claro, SP, Brazil - eISSN: 1980-6574 - under a license Creative Commons - Version 4.0 